\title{
Effects of breathing exercises on breathing pattern and thoracoabdominal motion after gastroplasty,***
}

\author{
Efeitos de exercícios respiratórios sobre o padrão respiratório e \\ movimento toracoabdominal após gastroplastia
}

\author{
Georgia Miranda Tomich, Danielle Corrêa França, Marco Túlio Costa Diniz, \\ Raquel Rodrigues Britto, Rosana Ferreira Sampaio, Verônica Franco Parreira
}

\begin{abstract}
Objective: To evaluate breathing pattern and thoracoabdominal motion during breathing exercises. Methods: Twenty-four patients with class 11 or 111 obesity (18 women; 6 men) were studied on the second postoperative day after gastroplasty. The mean age was $37 \pm 11$ years, and the mean BMl was $44 \pm 3 \mathrm{~kg} / \mathrm{m}^{2}$. Diaphragmatic breathing, incentive spirometry with a flow-oriented device and incentive spirometry with a volume-oriented device were performed in random order. Respiratory inductive plethysmography was used in order to measure respiratory variables and thoracoabdominal motion. Results: Comparisons among the three exercises showed significant differences: tidal volume was higher during incentive spirometry (with the flow-oriented device or with the volume-oriented device) than during diaphragmatic breathing; the respiratory rate was lower during incentive spirometry with the volume-oriented device than during incentive spirometry with the flow-oriented device; and minute ventilation was higher during incentive spirometry (with the flow-oriented device or with the volume-oriented device) than during diaphragmatic breathing. Rib cage motion did not vary during breathing exercises, although there was an increase in thoracoabdominal asynchrony, especially during incentive spirometry with the flow-oriented device. Conclusions: Among the breathing exercises evaluated, incentive spirometry with the volume-oriented device provided the best results, because it allowed slower, deeper inhalation.
\end{abstract}

Keywords: Breathing exercises; Physical therapy (Specialty); Bariatric surgery; Obesity, morbid.

\section{Resumo}

Objetivo: Avaliar o padrão respiratório e o movimento toracoabdominal durante exercícios respiratórios. Métodos: Vinte e quatro pacientes com obesidade de nível 11 e 111 (18 mulheres; 6 homens) foram estudados no segundo dia pós-operatório após gastroplastia. A média de idade era de $37 \pm 11$ anos, e a média de IMC era de $44 \pm 3 \mathrm{~kg} / \mathrm{m}^{2}$. Exercício diafragmático, espirometria de incentivo orientada a fluxo e espirometria de incentivo orientada a volume foram realizados em ordem aleatória. A pletismografia respiratória indutiva foi utilizada para avaliar variáveis do padrão respiratório e do movimento toracoabdominal. Resultados: As comparações entre os exercícios demonstraram diferenças significativas: maior volume corrente durante a espirometria de incentivo orientada a fluxo ou orientada a volume (vs. exercício diafragmático), menor frequência respiratória durante a espirometria de incentivo orientada a volume (vs. espirometria de incentivo orientada a fluxo), e maior ventilação minuto durante a espirometria de incentivo orientada a fluxo ou orientada a volume (vs. exercício diafragmático). 0 movimento toracoabdominal não foi modificado durante os exercícios respiratórios e houve um aumento na assincronia toracoabdominal, especialmente durante a espirometria de incentivo orientada a fluxo. Conclusões: Entre os exercícios respiratórios avaliados, a espirometria de incentivo orientado a volume forneceu os melhores resultados, pois possibilitou uma inspiração mais lenta e profunda.

Descritores: Exercícios respiratórios; Fisioterapia (Especialidade); Cirurgia bariátrica; Obesidade mórbida.

\footnotetext{
* Study carried out at the Universidade Federal de Minas Gerais - UFMG, Federal University of Minas Gerais - Belo Horizonte, Brazil. Correspondence to: Verônica F. Parreira. Universidade Federal de Minas Gerais, DFIT-EEFFTO, Laboratório de Avaliação e Pesquisa em Desempenho Cardiorrespiratório, Avenida Antônio Carlos, 6627, CEP 31270-901, Belo Horizonte, MG, Brasil.

Tel 5531 3409-4794.Fax 5531 3409-4783.E-mail: parreira@ufmg.br or veronica.parreira@pesquisador.cnpq.br

Financial support: This study received partial financial support from the Fundação de Amparo à Pesquisa do Estado de Minas Gerais (FAPEMIG, Foundation for the Support of Research in the state of Minas Gerais; grant no. CDS-APQ-5350-5.01/07) and the Conselho Nacional de Desenvolvimento Científico e Tecnológico (CNPq, National Council for Scientific and Technological Development; grant no. 309145/2007-4). Georgia M. Tomich is the recipient of a fellowship from the Coordenação de Aperfeiçoamento de Pessoal de Nivel Superior (CAPES, Coordination of the Advancement of Higher Education).

Submitted: 16 July 2009. Accepted, after review: 5 November 2009.

** A versão completa em português deste artigo está disponível em www.jornaldepneumologia.com.br
} 


\section{Introduction}

Chest physiotherapy, including deep breathing exercises, is part of the postoperative treatment for respiratory dysfunctions. ${ }^{(1)}$ The slow, deep voluntary inhalations increase functional residual capacity, ensure greater alveolar stability, ${ }^{(1)}$ and can be performed with or without mechanical devices. Slow, deep inhalations performed without a mechanical device constitute the foundation of respiratory exercises, such as diaphragmatic breathing (DB). ${ }^{(2)}$ In contrast, the incentive spirometry (IS) technique can be used. ${ }^{(1)}$

As a therapeutic breathing exercise, DB has been used in clinical practice for decades. Earlier studies have investigated the efficacy of deep breathing exercises associated with other forms of treatment, ${ }^{(3,4)}$ making it difficult to delineate its effects. ${ }^{(5,6)}$ In the 1970s, IS was introduced by Bartlett et al. ${ }^{(1)}$ with the purpose of encouraging, by means of visual feedback, the performance of sustained maximal inspiration..$^{(1,7)}$ Few studies have evaluated the specific effects of $\mathrm{DB}^{(5,8)}$ or IS in the postoperative period ${ }^{(9-11)}$ or the impact that the use of different devices has on therapeutic efficacy. ${ }^{(12-14)}$

The therapeutic effect and the performance of slow, deep inhalations in the postoperative period can be influenced by different factors. Upper abdominal surgery has a greater impact on respiratory function than does lower abdominal surgery. One of the risk factors for postoperative pulmonary complications (PPCs) reported in the literature is obesity, ${ }^{(15)}$ a condition that might cause adverse effects on the respiratory system because of alterations in the respiratory mechanics, in pulmonary gas exchange and in breathing control. ${ }^{(16,17)}$ One group of authors ${ }^{(15)}$ evaluated the effects of chest physiotherapy following abdominal surgery in 368 patients. A higher incidence of PPCs was found in obese patients when compared with those who were not obese, and a particularly beneficial effect of chest physiotherapy was observed in the obese patients.

Although various treatment regimens have been used, there is still no specific and universally accepted therapeutic concept. ${ }^{(18)}$ it is known, however, that techniques or devices that encourage the patient to perform deep inhalations are clinically important ${ }^{(10)}$ and widely used. Only a few studies have compared DB and IS, both of which are based on slow, deep inhalations, and, to our knowledge, none of those studies included obese patients.

The purpose of this study was to evaluate breathing pattern and thoracoabdominal motion in obese patients following gastroplasty during breathing at rest, DB, IS with a flow-oriented device (ISFOD) and IS with a volume-oriented device (ISVOD), considering the physiological basis of these techniques.

\section{Methods}

Participants were selected from among obese patients admitted for elective gastroplasty at a university hospital. The inclusion criterion was having been submitted to open gastric bypass surgery through Roux-en-Y vertical banded gastroplasty (Capella technique). The exclusion criteria were the following: inability to perform the procedures and pain intensity $>5$ on a numerical rating scale. The research ethics committee of the institution approved the study, and all patients gave written informed consent.

Respiratory inductive plethysmography (RIP; Respitrace; NIMS Inc., Miami, FL, USA) was used to obtain breathing pattern and thoracoabdominal motion variables. Other authors have used RIP in order to assess the breathing pattern of subjects in health or disease. ${ }^{(19)}$ Teflon-coated inductance coils of appropriate sizes were placed around the rib cage and the abdomen; the upper edge of the rib cage band was placed at the level of the axilla; and the abdominal band was placed at the level of the umbilicus. ${ }^{(13)}$ The calibration procedure was performed using the qualitative diagnostic calibration. ${ }^{(20)}$

We determined individual values for tidal volume $\left(\mathrm{V}_{\mathrm{T}}\right)$, respiratory rate $(\mathrm{RR})$, minute ventilation $\left(V_{E}\right)$, inspiratory time $\left(T_{1}\right)$, expiratory time $\left(T_{E}\right)$, total respiratory time $\left(T_{\text {tot }}\right)$, inspiratory duty cycle $\left(T_{1} / T_{\text {tot }}\right)$, mean inspiratory flow $\left(V_{T} / T_{1}\right)$, contribution of the rib cage motion to $\mathrm{V}_{\mathrm{T}}\left(\% \mathrm{RC} / \mathrm{V}_{\mathrm{T}}\right)$, phase relation during inhalation (PRI), phase angle (PA) and labored breathing index (LBI). The last three variables reflect thoracoabdominal asynchrony. ${ }^{(19)}$

Data were collected on the second postoperative day, including gender, age, weight, height, $\mathrm{BMl}$ and smoking history, as well as current and past medical history. Information on the surgery was also collected. The bands of the RIP equipment were positioned with the patients sitting up 
in bed. Subsequently, an angle of $30^{\circ}$ between the head of the bed and a horizontal line was measured using a goniometer. The patients were then instructed to lie comfortably in a semireclined position, avoiding any shift of the body during the recording.

While performing the three breathing exercises, all of the patients were instructed to take slow, deep breaths, trying to displace the abdomen more than the rib cage, and to exhale. During DB, the hands of the researcher were placed below the lower costal margin of the subject, who was instructed to inhale, to maximize the abdominal displacement and to avoid rib cage motion. ${ }^{(2)}$ During exercises with ISFOD and ISVOD (TriFlo 11 and Voldyne spirometers, respectively; Hudson $\mathrm{RCl}$, Temecula, CA, USA), patients were instructed to inhale via a mouthpiece.

A custom-made random number generator program (MatLab, Natick, MA, USA) was used in assigning the order in which the breathing exercises would be performed. After the calibration of the RIP device, recordings were made for a baseline period of at least $4 \mathrm{~min}$, after which the first randomly selected breathing exercise (DB, ISFOD or 1SVOD) was performed. Prior to each of the two remaining breathing exercises, new baseline data were obtained. For each exercise, 5-10 cycles were recorded. Immediately before and after each of the three breathing exercises, pain intensity was measured.

The sample size was calculated based on a pilot study involving the first 10 patients. Taking into consideration a level of significance of 0.05 and a power of 0.80 , the minimum sample size was determined to be 23 participants. Data are presented as means and standard deviations. The analysis of the distribution of data was performed using the Kolmogorov-Smirnov test. Comparisons between baseline values or between these and those obtained with the exercises were performed using ANOVA for repeated measures, with Bonferroni correction, considering the number of comparisons made $(\alpha=0.017$ between baseline periods and $\alpha=0.008$ between baseline and exercise values). Tukey's post hoc test or the Friedman and Wilcoxon tests were used for pairwise comparisons. Correlations were tested with Pearson's or Spearman's rho. The level of significance was set at 0.05. The data were analyzed with the Statistical Package for the Social Sciences, version 10 (SPSS Inc., Chicago, lL, USA).

\section{Results}

We included 26 patients with class 11 obesity (BMl ranging from 35.0 to $39.9 \mathrm{~kg} / \mathrm{m}^{2}$ in association with comorbidities) or class 111 obesity (BMl $\geq 40 \mathrm{~kg} / \mathrm{m}^{2}$ ) who had been admitted for elective gastroplasty at a university hospital. Two patients were excluded for the following reasons: the level of pain reported was $>5$ even prior to the exercises (1 subject); and there were technical problems during the calibration procedure (1 subject).

Therefore, 24 patients were studied ( 18 women and 6 men; mean age $=37 \pm 11$ years; mean weight $=123 \pm 21 \mathrm{~kg}$; mean height $=1.67 \pm$ $0.13 \mathrm{~m}$; and mean BMl $=44 \pm 3 \mathrm{~kg} / \mathrm{m}^{2}$ ). Comorbidities associated with obesity were present in 16 patients (54\% of whom presented hypertension). The mean duration of surgery was $144 \pm 24 \mathrm{~min}$, and the mean duration of anesthesia was $170 \pm 32 \mathrm{~min}$. Medications were administered according to medical protocols. In the postoperative period, hospital professionals applied physical therapy protocols when necessary.

Data were obtained during the three baseline periods and the three breathing exercise periods for all 23 patients. One of the patients was unable to perform the third baseline period and third breathing exercise (ISFOD) because of somnolence. Some periods of RIP recording during the performance of the breathing exercises had to be excluded from the analysis because of excessive artifacts and irregularities: 5 during DB; 1 during ISFOD; and 2 during ISVOD. A total of 274 cycles during breathing exercise periods were analyzed: 82 cycles during DB; 99 during ISFOD; and 93 during 1SVOD. Regarding the three baseline periods, a total of 1,658 respiratory cycles were analyzed: 581 cycles during the first baseline period; 559 during the second baseline period; and 518 during the third baseline period, with a mean value of $23 \pm 7$ cycles per subject. For obtaining the baseline data, means were calculated from the last one-minute measurements of each steady state period.

Regarding baseline data, breathing pattern and thoracoabdominal motion, there were no significant differences among the three baseline periods for the following respiratory variables: 
Table 1 - Respiratory variables during the baseline period, diaphragmatic breathing, incentive spirometry with a flow-oriented device and incentive spirometry with a volume-oriented device following gastroplasty.,

\begin{tabular}{|c|c|c|c|c|}
\hline \multirow[t]{2}{*}{ Variable } & Baseline & DB & ISFOD & ISVOD \\
\hline & $(n=24)$ & $(n=19)$ & $(n=22)$ & $(n=22)$ \\
\hline $\mathrm{V}_{\mathrm{T}}, \mathrm{mL}$ & $384.99 \pm 71.65$ & $753.43 \pm 363.20^{* *}$ & $951.04 \pm 253.29^{* * * * * *}$ & $1042.04 \pm 377.62^{* * * * * * *}$ \\
\hline $\mathrm{RR}$, cycles/min & $20.86 \pm 7.26$ & $9.66 \pm 2.27^{* *}$ & $13.06 \pm 5.50^{* *}$ & $9.84 \pm 3.65^{* *, * * * *}$ \\
\hline $\mathrm{V}_{\mathrm{E}}, \mathrm{L} / \mathrm{min}$ & $7.64 \pm 2.11$ & $6.98 \pm 2.65$ & $12.05 \pm 4.83^{* *, * * * *}$ & $9.83 \pm 3.74^{* * * *}$ \\
\hline $\mathrm{T}_{1}, \mathrm{~s}$ & $1.37 \pm 0.66$ & $2.86 \pm 0.88^{* * *}$ & $2.43 \pm 1.28$ & $3.19 \pm 1.19^{* *}$ \\
\hline $\mathrm{T}_{\mathrm{E}}, \mathrm{s}$ & $2.08 \pm 1.17$ & $3.75 \pm 0.99^{* * *}$ & $3.00 \pm 1.31^{* *}$ & $3.73 \pm 1.40^{* *}$ \\
\hline $\mathrm{T}_{\text {tot }}, \mathrm{s}$ & $3.46 \pm 1.80$ & $6.61 \pm 1.55^{* * *}$ & $5.44 \pm 2.14^{* * *}$ & $6.91 \pm 2.37^{* * * * * * * * *}$ \\
\hline $\mathrm{T}_{1} /$ Ttot & $0.40 \pm 0.04$ & $0.43 \pm 0.08$ & $0.44 \pm 0.10$ & $0.46 \pm 0.07^{* *}$ \\
\hline $\mathrm{V}_{\mathrm{T}} / \mathrm{T}_{1}, \mathrm{~mL} / \mathrm{s}$ & $315.53 \pm 80.97$ & $295.30 \pm 145.72$ & $480.88 \pm 221.45^{* * * *}$ & $373.12 \pm 168.44$ \\
\hline$\% \mathrm{RC} / \mathrm{V}_{\mathrm{T}}$ & $59.19 \pm 24.67$ & $75.52 \pm 32.91$ & $81.71 \pm 29.49$ & $71.34 \pm 29.09$ \\
\hline PRI, \% & $24.55 \pm 18.81$ & $43.79 \pm 18.28^{* *}$ & $41.22 \pm 20.53^{* *}$ & $35.45 \pm 16.93$ \\
\hline 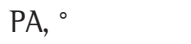 & $32.79 \pm 39.29$ & $72.85 \pm 55.52$ & $70.25 \pm 54.25^{* *}$ & $54.56 \pm 43.29^{* * *}$ \\
\hline $\mathrm{LBl}$ & $1.25 \pm 0.13$ & $1.37 \pm 0.15$ & $1.35 \pm 0.25$ & $1.29 \pm 0.14$ \\
\hline
\end{tabular}

DB: diaphragmatic breathing; ISFOD: incentive spirometry with a flow-oriented device; ISVOD: incentive spirometry with a volume-oriented device; $\mathrm{V}_{\mathrm{T}}$ : tidal volume; RR: respiratory rate; VE: minute ventilation; $\mathrm{T}_{1}$ : inspiratory time; $\mathrm{T}_{\mathrm{E}}$ : expiratory time; $\mathrm{T}_{\text {tot }}$ : total respiratory time; $\mathrm{T}_{\mathrm{I}} / \mathrm{T}_{\text {tot }}$ : inspiratory duty cycle; $\mathrm{V}_{\mathrm{T}} / \mathrm{T}_{\mathrm{I}}$ : mean inspiratory flow; $\% \mathrm{RC} / \mathrm{V}_{\mathrm{T}}$ : contribution of rib cage motion to tidal volume; PA: phase angle; PRl: phase relation during inhalation; LBI: labor breathing index. ${ }^{a}$ Data are presented as mean $\pm \mathrm{SD}$. *Comparisons were performed with ANOVA for repeated measures $(\alpha=0.008)$, with Tukey's post hoc test $\left(\mathrm{V}_{\mathrm{E}}, \mathrm{T}_{1}, \mathrm{~T}_{\mathrm{E}}, \mathrm{T}_{1} / \mathrm{T}_{\text {tot }}, \mathrm{V}_{\mathrm{T}} / \mathrm{T}_{1}\right.$ and \%RC/VT), or the Friedman and Wilcoxon tests $\left(\mathrm{V}_{\mathrm{T}}, \mathrm{RR}, \mathrm{T}_{\text {tot }}\right.$, PRI, PA and LBI). ${ }^{* *}$ Statistically significant difference vs. baseline. ${ }^{* * *}$ Statistically significant difference vs. DB. ${ }^{* * * *}$ Statistically significant difference vs. ISVOD.

$\mathrm{V}_{\mathrm{T}}, \mathrm{RR}, \mathrm{V}_{\mathrm{E}}, \% \mathrm{RC} / \mathrm{V}_{\mathrm{T}}$ and $\mathrm{PA}(\mathrm{p}=0.028 ; \mathrm{p}=0.438$ $p=0.132 ; p=0.676$; and $p=0.878$; respectively). Therefore, the analysis was performed considering the data obtained during the first baseline period.

Table 1 shows the data regarding breathing pattern and thoracoabdominal motion during the baseline period and during the three breathing exercise periods. Comparisons between baseline values and breathing exercise values showed a significant increase in $\mathrm{V}_{\mathrm{T}}$ and a significant decrease in RR during all exercises ( $p<0.001)$, with a significant increase in $V_{E}$ only during ISFOD ( $p=0.006)$. There was an increase in $T_{1}$ during DB and ISVOD ( $p<0.001)$, in $T_{E}$ and $\mathrm{T}_{\text {tot }}$ during all breathing exercises $(\mathrm{p}=0.006)$, and in $T_{1} / T_{\text {tot }}$ only during ISVOD $(p=0.006)$. Comparisons among the three types of exercises showed higher $\mathrm{V}_{\mathrm{T}}$ during ISFOD and ISVOD than during DB $(p=0.002$ and $p=0.001$, respectively). In addition, RR was lower during ISVOD than during 1SFOD $(p=0.004)$, and $V_{E}$ was higher during ISFOD and ISVOD than during DB ( $p=0.005$ and $p=0.001$, respectively). A higher $\mathrm{T}_{\text {tot }}$ was observed during ISVOD than during ISFOD $(p=0.005)$. Furthermore, $V_{T} / T_{1}$ was higher during ISFOD than during DB ( $p=0.005)$. The majority of the patients were able to raise only the first ball during 1SFOD.

There were no significant changes in \%RC/ $V_{T}(p=0.021)$ or LBl $(p=0.069)$ when baseline and breathing exercise values were compared. Regarding PRI and PA, variables related to thoracoabdominal asynchrony, there was a significant increase in PRI during DB and ISFOD ( $p=0.007$ and $p=0.001$, respectively) and a significant increase in PA during 1SFOD and ISVOD when compared with the baseline period $(p=0.001$ and $p=0.007$, respectively). Comparisons among the exercises showed no significant differences. The analysis of correlations between $\% R C / \mathrm{V}_{\mathrm{T}}$ and other thoracoabdominal motion variables, based on baseline and breathing exercise values, showed significant, moderate-to-strong positive correlations. High values of $\% R C / \mathrm{V}_{\mathrm{T}}$ correlated with high values of PRI $(r=0.837 ; p<0.001)$, $\mathrm{PA}(\mathrm{r}=0.587, \mathrm{p}<0.001)$ and $\mathrm{LBl}(\mathrm{r}=0.773$; $p<0.001)$.

\section{Discussion}

The present study was conducted in order to evaluate the influence of three different breathing exercises on variables regarding breathing pattern and thoracoabdominal 
motion, measured in obese patients following open elective gastroplasty. The three breathing exercises modified these respiratory variables when compared with breathing at rest, showing differences among the exercises. In the comparisons between baseline and exercise periods, there was an increase in $\mathrm{V}_{\mathrm{T}}$ and a decrease in RR during all exercises. However, there was an increase in $\mathrm{V}_{\mathrm{E}}$ only during 1SFOD, as well as a significant increase in $\mathrm{T}_{1} / \mathrm{T}_{\text {tot }}$ only during ISVOD. The combination of high $\mathrm{V}_{\mathrm{T}}$, low RR and high $\mathrm{T}_{1} /$ $\mathrm{T}_{\text {tot }}$ should be considered as the best performance during these breathing exercises. In the present study, this result was reached during 1SVOD. Regarding thoracoabdominal motion, there were no significant changes in $\% R C / V_{T}$, and there was an increase in thoracoabdominal asynchrony during all exercises, without differences among them.

As expected in breathing exercises based on deep inhalations, ${ }^{(21)} V_{\mathrm{T}}$ was significantly higher during all three of the exercises, with an increase ranging from 2 to almost 3 times during the exercises when compared with the baseline periods. Higher transpulmonary pressure leads to a higher $\mathrm{V}_{\mathrm{T}}$, which can reopen collapsed alveoli and consequently lead to an increased recruitment of alveoli. ${ }^{(7,21)}$ This is especially important if we consider that respiratory alterations caused by abdominal surgery can be more pronounced in obese subjects, which can further increase the occurrence of alveolar collapse. A combination of factors, such as lower lung and chest wall compliance, higher lung resistance and overstretching of the diaphragm, might influence the respiratory system in obese patients, resulting in decreased lung volumes and capacities, especially functional residual capacity. ${ }^{(16,22)}$

Comparisons among the three exercises showed that $\mathrm{V}_{\mathrm{T}}$ was significantly higher during 1SFOD and 1SVOD than during DB. It can be speculated that this difference is partially attributable to the way in which IS was performed: the subject inhaled through the mouth via a mouthpiece connected to a tube. This can increase the dead space and thereby increase $\mathrm{V}_{\mathrm{T}}{ }^{(23)} \mathrm{ln}$ addition, during $1 \mathrm{~S}$, there is a target to be achieved and the subject receives feedback, which can function as a motivating factor. During DB, this factor is not present. ${ }^{(5)}$

As expected during slow, deep inhalations, RR was lower during all exercises than during the baseline period. Comparisons among the exercises showed a significantly lower RR during ISVOD than during ISFOD. A significant increase in $V_{E}$ occurred only during ISFOD in comparison with baseline values, and $\mathrm{V}_{\mathrm{E}}$ was significantly higher during ISFOD and ISVOD than during DB. A higher $\mathrm{V}_{\mathrm{E}}$ can decrease the risk of hypoxemia. (24) However, considering $V_{E}$ as a product of $V_{T}$ and RR, a higher $V_{E}$ during ISFOD was mainly determined by a higher RR. During slow, deep inhalations (i.e., when the flow rate is low), a low RR is expected in order to contribute to a uniform distribution of inhaled gas through the pulmonary parenchyma. As RR increases, ventilation tends to be higher where there is a lower airway resistance. Therefore, high values of RR contribute to increasing the work of breathing. ${ }^{(22)}$

An additional increase in the work of breathing can be detrimental in obese subjects, especially in the postoperative period, because obesity per se causes an increase in the work of breathing and in the cost of breathing, consequent to altered lung and chest wall components. ${ }^{(22,25)}$ During 1S, the device imposes additional work of breathing, which depends on a few characteristics, such as the diameter of the spirometer cylinder, the shape/weight of the plate, and the ball that is lifted by means of inspiratory effort. In the postoperative period, the levels of additional imposed work of breathing have been shown to be higher during 1SFOD than during ISVOD. ${ }^{(12)}$ Therefore, it seems that a more adequate performance during slow, deep inhalations in the postoperative period is more easily achieved with 1SVOD than with 1SFOD.

Regarding time variables related to breathing pattern, there were increases (in $\mathrm{T}_{1}$ during $\mathrm{DB}$ and ISVOD; in $\mathrm{T}_{\mathrm{E}}$ and $\mathrm{T}_{\text {tot }}$ during all breathing exercises; and in $T_{1} / T_{\text {tot }}$ during ISVOD) in comparison with the baseline values. In the present study, mean values of $T_{1} / T_{\text {tot }}$ at rest and during the exercises were similar to those found by one group of authors ${ }^{(5)}$ who evaluated the breathing pattern of obese subjects at rest and during different breathing exercises, including deep breathing, using body plethysmography. In our study, an increase in $\mathrm{T}_{\text {tot }}$ during DB and ISVOD was caused by increases in $T_{1}$ and $T_{E}$, whereas there was no significant increase in $T_{1}$ during ISFOD. This can be related to a higher RR and can represent a disadvantage to DB and ISVOD. 
However, a significantly higher $T_{1} / T_{\text {tot }}$ during ISVOD can be considered an advantage.

There was a higher $\mathrm{V}_{\mathrm{T}} / \mathrm{T}_{1}$ during ISFOD than during DB. It is known that when the inspiratory flow is too fast, it impedes uniform distribution of the inhaled gas and impairs ventilation in the base of the lungs. ${ }^{(26)}$ Another aspect to be considered is related to $\mathrm{V}_{\mathrm{T}} / \mathrm{T}_{1}$ during ISFOD: the majority of the patients were able to raise only the first ball, which corresponds to an inspiratory flow rate of $600 \mathrm{~mL} / \mathrm{s}$ according to the manufacturer, but does not correspond to the mean value of $V_{T} / T_{1}$ obtained. This difference between what was performed and what was measured during $1 \mathrm{~S}$ has been previously reported. ${ }^{(14)}$

All of the exercises caused statistically significant changes in $\% R C / V_{T}$ when compared with baseline values. Rib cage motion predominated over abdominal motion during the baseline period and especially during the exercises. Considering that the measurement of the regional excursion of the chest and of the abdomen is a potential means of detecting altered gas distribution, the predominance of rib cage motion can be related to greater ventilation in the upper parts of the lungs and less ventilation in the base of the lungs. ${ }^{(8)}$ The patients were instructed to try to displace the abdomen more than the rib cage during the exercises. Additionally, there was a manual stimulus during DB, which did not increase abdominal displacement. Different factors related to upper abdominal surgical procedures or obesity, such as higher abdominal pressure and diaphragmatic dysfunction, might have contributed to this fact. ${ }^{(27,28)}$ Based on our review of the literature, no previous studies have evaluated thoracoabdominal motion in obese patients after surgery. Therefore, there was a lack of data for comparisons.

Regarding thoracoabdominal asynchrony, there was a significant increase in PRI during DB and 1SFOD, as well as a significant increase in PA during 1SFOD and 1SVOD when these were compared with their respective baseline values, with no significant differences among the three exercises. Higher values of these variables during the exercises than at rest indicate increased thoracoabdominal asynchrony. High values of $\% R C / V_{T}$ correlated with high values of $\mathrm{PRI}, \mathrm{PA}$ and $\mathrm{LBl}$, which are parameters related to thoracoabdominal asynchrony. Another group of authors ${ }^{(29)}$ reported that increased thora- coabdominal asynchrony was associated with increased respiratory load, as was an increase in rib cage motion and in the variability of rib cage motion. Deep breathing exercises can represent an additional load to the respiratory system of obese subjects, influenced by the deposition of fat over the chest wall, which can lead to a change in the balance of elastic recoil between the chest wall and the lung, as well as changes in the compliance of the chest wall and impairment of muscle strength. ${ }^{(30)}$

In one controlled study, ${ }^{(15)}$ it was reported that chest physiotherapy applied prior to major abdominal surgery effectively reduced the risk of PPCs. The rate of these complications decreased by a factor of 4.5 in all patients and by a factor of 3.4 in high-risk patients. In obese patients, this factor was 7.0, indicating a particularly beneficial effect of chest physiotherapy in this group.

The end-inspiratory pause, in order to prevent atelectasis, is an important component of deep breathing exercises and is as important as the inspiratory volume reached. ${ }^{(7)}$ In this study, patients were instructed to perform exercises without end-inspiratory pauses because of the difficulty in controlling their duration, and this can be considered a limitation of the study.

In conclusion, among the breathing exercises evaluated, ISVOD provided the best results, because it allowed slower, deeper inhalation. These results contribute to the understanding of the influence that three breathing exercises in which slow, deep inhalations are performed have in obese patients following gastroplasty. Differences among the breathing exercises and their potential impact on therapeutic efficacy should be considered in clinical practice according to the clinical goals.

\section{References}

1. Bartlett RH, Gazzaniga AB, Geraghty TR. Respiratory maneuvers to prevent postoperative pulmonary complications. A critical review. JAMA. 1973;224(7):1017-21.

2. Gosselink HA. Breathing exercises in patients with chronic obstrutive pulmonary disease - An experimental study on the efficiency and coordination of breathing [thesis]. Amsterdam: Vrije Universiteit te Amsterdam; 1991.

3. Davies BL, MacLeod JP, Ogilvie HM. The efficacy of incentive spirometers in post-operative protocols for low-risk patients. Can J Nurs Res. 1990;22(4):19-36.

4. Brasher PA, McClelland KH, Denehy L, Story 1. Does removal of deep breathing exercises from a physiotherapy 
program including pre-operative education and early mobilisation after cardiac surgery alter patient outcomes? Aust J Physiother. 2003;49(3):165-73.

5. Olsén MF, lönroth $H$, Bake B. Effects of breathing exercises on breathing patterns in obese and non-obese subjects. Clin Physiol. 1999;19(3):251-7.

6. Westerdahl E, Lindmark B, Eriksson T, Hedenstierna G, Tenling A. The immediate effects of deep breathing exercises on atelectasis and oxygenation after cardiac surgery. Scand Cardiovasc J. 2003;37(6):363-7.

7. Bakow ED. Sustained maximal inspiration--a rationale for its use. Respir Care. 1977;22(4):379-82.

8. Roussos CS, Fixley M, Genest J, Cosio M, Kelly S, Martin RR, etc. Voluntary factors influencing the distribution of inspired gas. Am Rev Respir Dis. 1977;116(3):457-67.

9. Pasquina P, Tramèr MR, Granier JM, Walder B. Respiratory physiotherapy to prevent pulmonary complications after abdominal surgery: a systematic review. Chest. 2006;130(6):1887-99.

10. Haeffener MP, Ferreira GM, Barreto SS, Arena R, Dall'Ago P. Incentive spirometry with expiratory positive airway pressure reduces pulmonary complications, improves pulmonary function and 6-minute walk distance in patients undergoing coronary artery bypass graft surgery. Am Heart J. 2008;156(5):900.e1-900.e8.

11. Freitas ER, Soares BG, Cardoso JR, Atallah AN. Incentive spirometry for preventing pulmonary complications after coronary artery bypass graft. Cochrane Database Syst Rev. 2007;(3):CD004466.

12. Weindler J, Kiefer RT. The efficacy of postoperative incentive spirometry is influenced by the devicespecific imposed work of breathing. Chest. 2001;119(6):1858-64.

13. Tomich GM, França DC, Diório AC, Britto RR, Sampaio RF, Parreira VF. Breathing pattern, thoracoabdominal motion and muscular activity during three breathing exercises. Braz J Med Biol Res. 2007;40(10):1409-17.

14. Parreira VF, Tomich GM, Britto RR, Sampaio RF. Assessment of tidal volume and thoracoabdominal motion using volume and flow-oriented incentive spirometers in healthy subjects. Braz J Med Biol Res. 2005;38(7):1105-12.

15. Fagevik Olsén M, Hahn 1, Nordgren S, Lönroth $H$, Lundholm K. Randomized controlled trial of prophylactic chest physiotherapy in major abdominal surgery. Br J Surg. 1997;84(11):1535-8.

16. Koenig SM. Pulmonary complications of obesity. Am J Med Sci. 2001;321(4):249-79.

17. Teixeira CA, Dos Santos JE, Silva GA, de Souza ES, Martinez JA. Prevalence of and the potential physiopathological mechanisms involved in dyspnea in individuals with class 11 or 111 obesity. J Bras Pneumol. 2007;33(1):28-35.

18. Overend TJ, Anderson CM, Lucy SD, Bhatia C, Jonsson $\mathrm{Bl}$, Timmermans C. The effect of incentive spirometry on postoperative pulmonary complications: a systematic review. Chest. 2001;120(3):971-8.

19. Sackner MA, Gonzalez H, Rodriguez M, Belsito A, Sackner DR, Grenvik S. Assessment of asynchronous and paradoxic motion between rib cage and abdomen in normal subjects and in patients with chronic obstructive pulmonary disease. Am Rev Respir Dis. 1984;130(4):588-93.

20. Sackner MA, Watson H, Belsito AS, Feinerman D, Suarez $\mathrm{M}$, Gonzalez G, et al. Calibration of respiratory inductive plethysmograph during natural breathing. J Appl Physiol. 1989;66(1):410-20.

21. Douce FH. Incentive spirometry and others aids to lung inflation. In: Barnes TA, editor. Core Textbook of Respiratory Care Practice. New York: Mosby; 1994. p. 231-41.

22. Luce JM. Respiratory complications of obesity. Chest. 1980;78(4):626-31.

23. Perez W, Tobin MJ. Separation of factors responsible for change in breathing pattern induced by instrumentation. J Appl Physiol. 1985;59(5):1515-20.

24. West JB. Mecânica da Respiração. In: West JB, editor. Fisiologia Respiratória Moderna. São Paulo: Manole; 1996. p. 83-108.

25. Pelosi P, Croci M, Ravagnan 1, Vicardi P, Gattinoni L. Total respiratory system, lung, and chest wall mechanics in sedated-paralyzed postoperative morbidly obese patients. Chest. 1996;109(1):144-51.

26. Altose MD. Mecânica pulmonar. In: Fishman AP, editor. Diagnóstico das doenças pulmonares. São Paulo: Manole; 1992. p. 179-92.

27. Simonneau G, Vivien A, Sartene R, Kunstlinger F, Samii $\mathrm{K}$, Noviant $\mathrm{Y}$, et al. Diaphragm dysfunction induced by upper abdominal surgery. Role of postoperative pain. Am Rev Respir Dis. 1983;128(5):899-903.

28. Joris J, Kaba A, Lamy M. Postoperative spirometry after laparoscopy for lower abdominal or upper abdominal surgical procedures. Br J Anaesth. 1997;79(4):422-6.

29. Tobin MJ, Guenther SM, Perez W, Mador MJ. Accuracy of the respiratory inductive plethysmograph during loaded breathing. J Appl Physiol. 1987;62(2):497-505.

30. Lazarus R, Gore CJ, Booth M, Owen N. Effects of body composition and fat distribution on ventilatory function in adults. Am J Clin Nutr. 1998;68(1):35-41. 


\section{About the authors}

Georgia Miranda Tomich

Physical Therapist. Universidade Federal de Minas Gerais - UFMG, Federal University of Minas Gerais - Belo Horizonte, Brazil.

\section{Danielle Corrêa França}

Physical Therapist. Universidade Federal de Minas Gerais - UFMG, Federal University of Minas Gerais - Belo Horizonte, Brazil.

\section{Marco Túlio Costa Diniz}

Adjunct Professor. Department of Surgery, Faculdade de Medicina da Universidade Federal de Minas Gerais - FM-UFMG, Federal University of Minas Gerais Medical School - Belo Horizonte, Brazil.

\section{Raquel Rodrigues Britto}

Associate Professor. Department of Physical Therapy, Universidade Federal de Minas Gerais - UFMG, Federal University of Minas Gerais - Belo Horizonte, Brazil.

\section{Rosana Ferreira Sampaio}

Associate Professor. Department of Physical Therapy, Universidade Federal de Minas Gerais - UFMG, Federal University of Minas Gerais - Belo Horizonte, Brazil.

\section{Verônica Franco Parreira}

Associate Professor. Department of Physical Therapy, Universidade Federal de Minas Gerais - UFMG, Federal University of Minas Gerais - Belo Horizonte, Brazil. 